\title{
Cauda equina syndrome in ankylosing spondylitis: a report of six cases
}

\author{
I. HASSAN \\ From the Wessex Neurological Centre, Southampton University Hospitals, Southampton
}

SYNOPSIS Six patients with ankylosing spondylitis and features of a cauda equina syndrome are described. The myelographic findings are discussed in relation to the pathogenesis of the disorder and its natural history. Present experience suggests that the cauda equina syndrome is a more common complication of ankylosing spondylitis than is usually thought.

The nervous system may be involved in ankylosing spondylitis as a result of atlantoaxial subluxation or spinal fractures and by development of a cauda equina syndrome (Matthews, 1968). In addition, an increased incidence of multiple sclerosis in patients with ankylosing spondylitis has been described recently (Thomas et al., 1974). Eighteen cases of ankylosing spondylitis complicated by a cauda equina syndrome have been reported (Bowie and Glasgow, 1961; Hauge, 1961; Lee and Waters, 1962; McGill, 1966; Matthews, 1968; Rosenkranz, 1971; Gordon and Yudell, 1973; Russell et al., 1973; Thomas et al., 1974). These cases are reviewed in Table 1. While this number suggests that the cauda equina syndrome is a rare complication of ankylosing spondylitis, the present study indicates that this complication is more common than is usually thought.

\section{CLINICAL MATERIAL}

This investigation is based on a study of six patients with ankylosing spondylitis who were referred to the Wessex Neurological Centre between 1967 and 1975 for investigation of their neurological complaints. In all six the diagnosis of ankylosing spondylitis had been established reliably on clinical and radiological grounds. The average age was 54 years (range 49 to 59 years) and the average duration of the spondylitis was 29 years (range 25 to 37 years). Tests for rheumatoid factor were negative in all the patients. Three patients (cases 4, 5, and 6) had experienced several attacks of iritis. There was radiological evidence of

Address for correspondence: 21 Weaverthorpe Road, Woodthorpe Nottingham.

(Accepted 18 August 1976.) pulmonary fibrosis in three patients (cases 2, 4, and 5). Five of the six patients had received radiotherapy for the ankylosing spondylitis (Table 2).

\section{CASE 1}

A 59 year old man was seen in 1967 because of pain in the outer border of his left foot which had been present for nine years. He had suffered from ankylosing spondylitis since 1940 and had received radiotherapy in 1946. Clinical examination revealed wasting and weakness of the left calf, the left ankle jerk and plantar response were absent, and there wase sensory loss in the fifth lumbar and upper four sacral dermatomes on the left side. Oil myelography revealed posteriorly situated lumbar cysts (Figs. 1 and $2)$. No progression in his neurological signs had occurred during a follow-up period of four years.

\section{CASE 2}

A 49 year old man was seen in 1968 because of numbness of the posterior surface of his left leg which had been present for nine years. He had suffered from ankylosing spondylitis for 30 years and had received radiotherapy in 1947 . On clinical examination there was wasting and weakness of both buttocks and calves, both ankle jerks and plantar responses were absent, and there was sensory loss in the fifth lumbar and in all the sacral dermatomes. He developed systemic arterial hypertension in 1973 but his neurological signs have not progressed.

\section{CASE 3}

A 49 year old man presented in 1968 with numbness of his left foot which had been present for four months. He had also noticed a poor urinary stream. 
TABLE 2

DETAILS OF SIX CASES OF CAUDA EQUINA SYNDROME IN ANKYLOSING SPONDYLITIS REPORTED IN THIS SERIES

\begin{tabular}{|c|c|c|c|c|c|c|c|}
\hline Case & Age & $\begin{array}{l}\text { sex } \\
r)\end{array}$ & $\begin{array}{l}\text { Duration } \\
\text { of } A S \\
(y r)\end{array}$ & $D X T$ & Neurological complaint & Neurological signs & Myelogram \\
\hline 1 & 59 & $\mathbf{M}$ & 27 & Yes & Pain in $L$ foot for $9 \mathrm{yr}$ & $\begin{array}{l}\text { Wasting and weakness of } \\
\text { L calf. Absent L ankle jerk. } \\
\text { Sensory loss L5-S5 (L) }\end{array}$ & Lumbar cysts \\
\hline 2 & 49 & $\mathbf{M}$ & 30 & Yes & $\begin{array}{l}\text { Numbness in back of } \mathrm{L} \mathrm{leg} \\
\text { for } 9 \mathrm{yr} \text {. Incontinence of } \\
\text { urine for } 3 \mathrm{~m}\end{array}$ & $\begin{array}{l}\text { Wasting and weakness of } \\
\text { calves and buttocks, absent } \\
\text { ankle jerks, sensory loss L5-S5 } \\
\text { (bilat.) }\end{array}$ & Not done \\
\hline 3 & 49 & $\mathbf{M}$ & 25 & No & Numbness in $\mathrm{L}$ foot for $4 \mathrm{~m}$ & $\begin{array}{l}\text { Wasting and weakness of calves } \\
\text { and buttocks, absent ankle } \\
\text { jerks, sensory loss S1-S5 } \\
\text { (bilat.) }\end{array}$ & Lumbar cysts \\
\hline 4 & 59 & $\mathbf{M}$ & 25 & Yes & Weakness of $\mathbf{R}$ foot for $3 \mathrm{yr}$ & $\begin{array}{l}\text { Wasting and weakness of } \\
R \text { calf, absent } R \text { ankle jerk, } \\
\text { sensory loss } S 1-S 2(R)\end{array}$ & Mid-thoracic cyst \\
\hline 5 & 54 & $\mathbf{M}$ & 28 & Yes & Incontinence of urine for $12 \mathrm{~m}$ & $\begin{array}{l}\text { Wasting and weakness of } \\
\text { calves and buttocks, absent } \\
\text { ankle jerks, sensory loss S1-S5 } \\
\text { (bilat.) }\end{array}$ & Lumbar cysts \\
\hline 6 & 55 & $\mathbf{F}$ & 37 & Yes & $\begin{array}{l}\text { Pain and neuropathic ulcers } \\
\text { in both legs for } 20 \mathrm{yr} \text {. } \\
\text { Incontinence of urine for } 4 \mathrm{~m}\end{array}$ & $\begin{array}{l}\text { Wasting and weakness of } \\
\text { calves and buttocks, absent } \\
\text { ankle jerks, sensory loss S1-S5 } \\
\text { L5 (bilat.) }\end{array}$ & Not done \\
\hline
\end{tabular}

He had suffered from ankylosing spondylitis for 25 years; he had never been treated with radiotherapy. There was wasting and weakness of both buttocks and calves, absent ankle jerks and plantar responses, and a sensory loss in all the sacral dermatomes. Oil myelography revealed posteriorly situated lumbar cysts. No progression in the neurological signs had occurred in three years.

\section{CASE 4}

A 59 year old man was referred in 1974 with weakness of plantar flexion of the right foot for three years. He had suffered from ankylosing spondylitis for 25 years and had received radiotherapy in 1950. Physical examination revealed wasting and weakness of his right calf, the right ankle jerk and plantar response were absent, and there was sensory loss in the first two sacral dermatomes on the right side. Oil myelography revealed posteriorly situated cysts in the mid thoracic region. No progression of the neurological signs has been noted during a follow-up period of one year.

\section{CASE 5}

A 54 year old man presented in 1975 with a history of urinary incontinence for 12 months. He gave a history of ankylosing spondylitis for 28 years and had been treated with radiotherapy to his cervical spine and hips in 1958 and 1971. On examination there was wasting and weakness of both buttocks and calves his ankle jerks and plantar responses were absent an the sensory loss affected all the sacral dermatomes A water soluble contrast radiculogram revealece multiple large diverticula situated posterolaterally and between the laminae in the lumbar region (Fig. $3 a$ and $b$ ).

\section{CASE 6}

A 55 year old woman with a 37 year history of ankylosing spondylitis was seen in 1975 . Since 1953 she had suffered from pain and neuropathic ulceration of both legs. She had been incontinent of urine for four months. She had received radiotherapy in 1946. Physical examination revealed wasting and weakness of both buttocks and calves, absent ankle jerks and plantar responses, and sensory loss in the fifth lumbar and all sacral dermatomes.

\section{DISCUSSION}

In the patients reported in this study the onset of the cauda equina syndrome occurred between 17 and 28 years after the onset of the ankylosing spondylitis, during periods when the disease was relatively inactive as judged by symptoms and erythrocyte sedimentation rates. The varied nature of the initial 


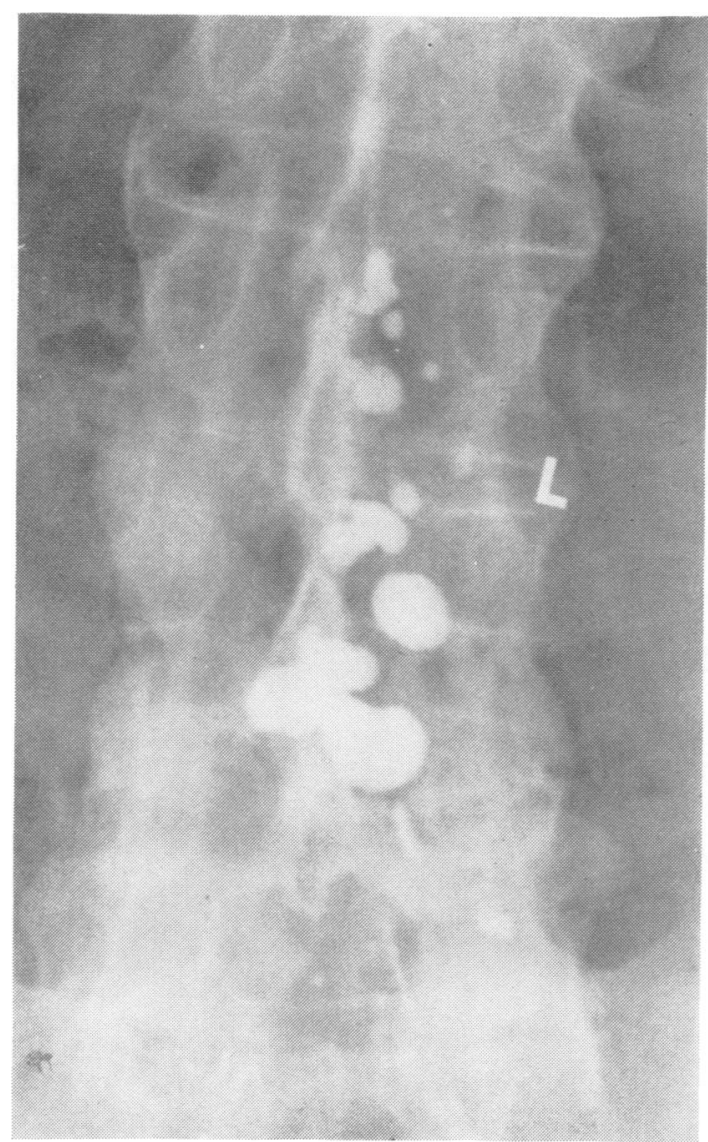

FIG. 1 Case 1. Oil myelogram showing posteriorly situated diverticula in the lumbar theca (patient supine).

neurological symptoms and their long duration account for the difficulty in early recognition of the cauda equina syndrome in patients with ankylosing spondylitis in whom pain in the buttocks and thighs may be attributed to sacroiliac joint inflammation.

Urinary incontinence was the presenting complaint in case 5 , in all three patients described by Bowie and Glasgow (1961), in cases 2 and 3 reported by Hauge (1961), in Rosenkrantz's (1971) case, in case 2 of Gordon and Yudell (1973), and in case 3 of Thomas et al. (1974). It subsequently became the most prominent symptom in the case described by Lee and Waters (1962), McGill (1966), and Matthews (1968) (case 4). Other presenting symptoms were pain, numbness or weakness in the lower limbs, impotence, and difficulties with micturition and defaecation.

The significance of posteriorly situated diverticula of the lumbar theca was first recognised by Matthews

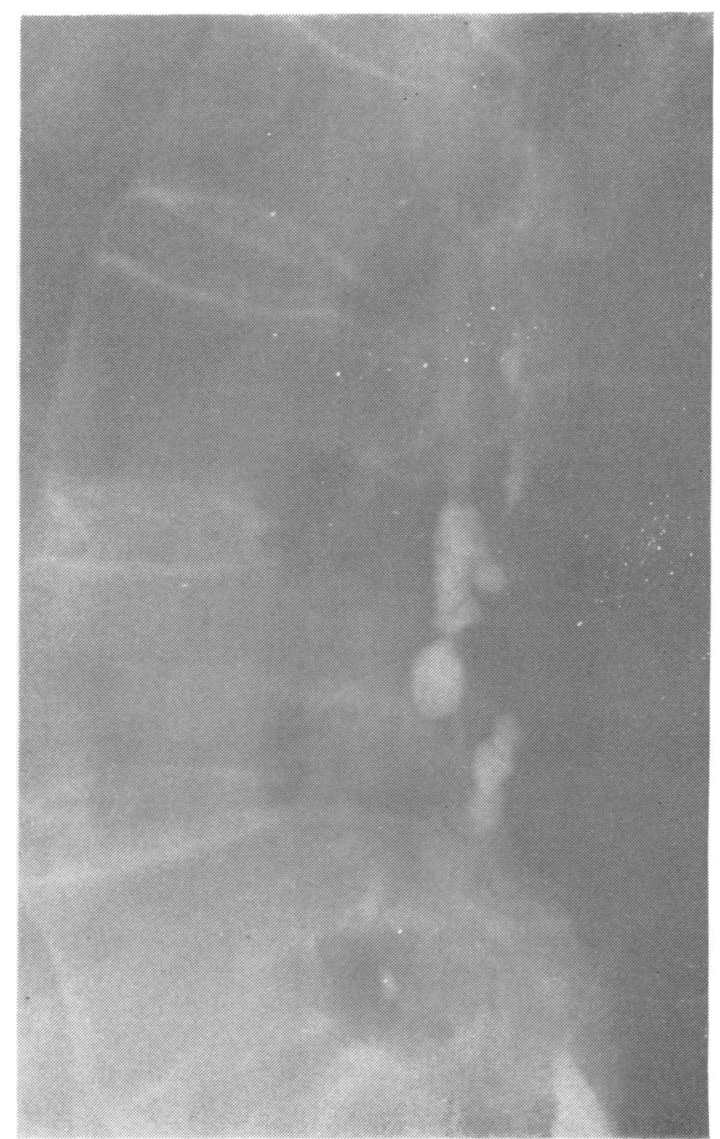

FIG. 2 Case 1. Oil myelogram showing posteriorly situated diverticula in the lumbar theca (patient supine).

(1968). They are now regarded as the characteristic myelographic features in this syndrome (Thomas et al., 1974). They have been recognised more frequently since patients have been examined additionally in the supine position during myelography. They were found in three of the six cases reported here (cases 1, 3, and 5), in two cases reported by Matthews (1968) and Russell and his colleagues (1968), and in one case each of McGill (1966), Rosenkrantz (1971), and Thomas et al. (1974). The additional examination of all patients in the supine position during myelography is essential for visualisation of diverticula, as posterior lesions will not fill with the patient prone and could be missed easily. This may account for the absence of diverticula in some of the reported cases (Table 1). Matthews (1968) described the necropsy findings in one patient in which it was shown that these diverticula extended backwards and encroached exten- 


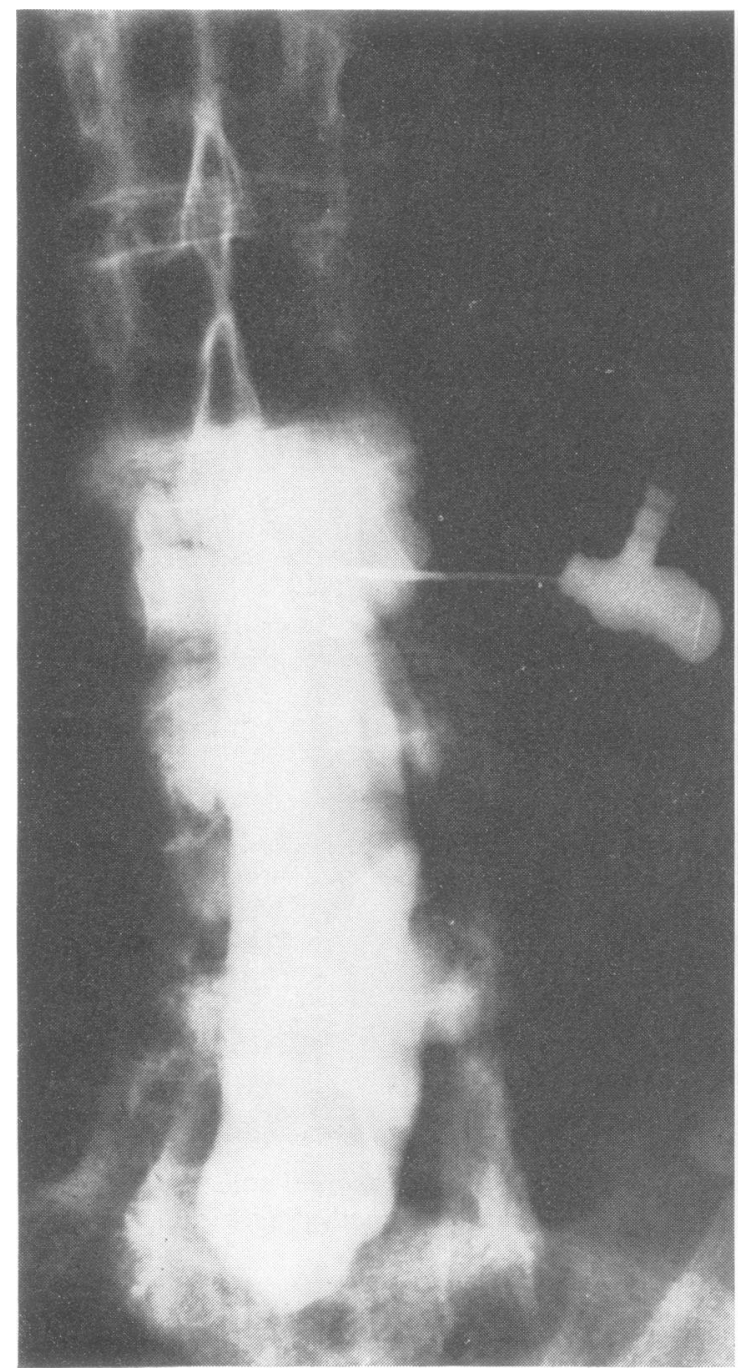

(a)

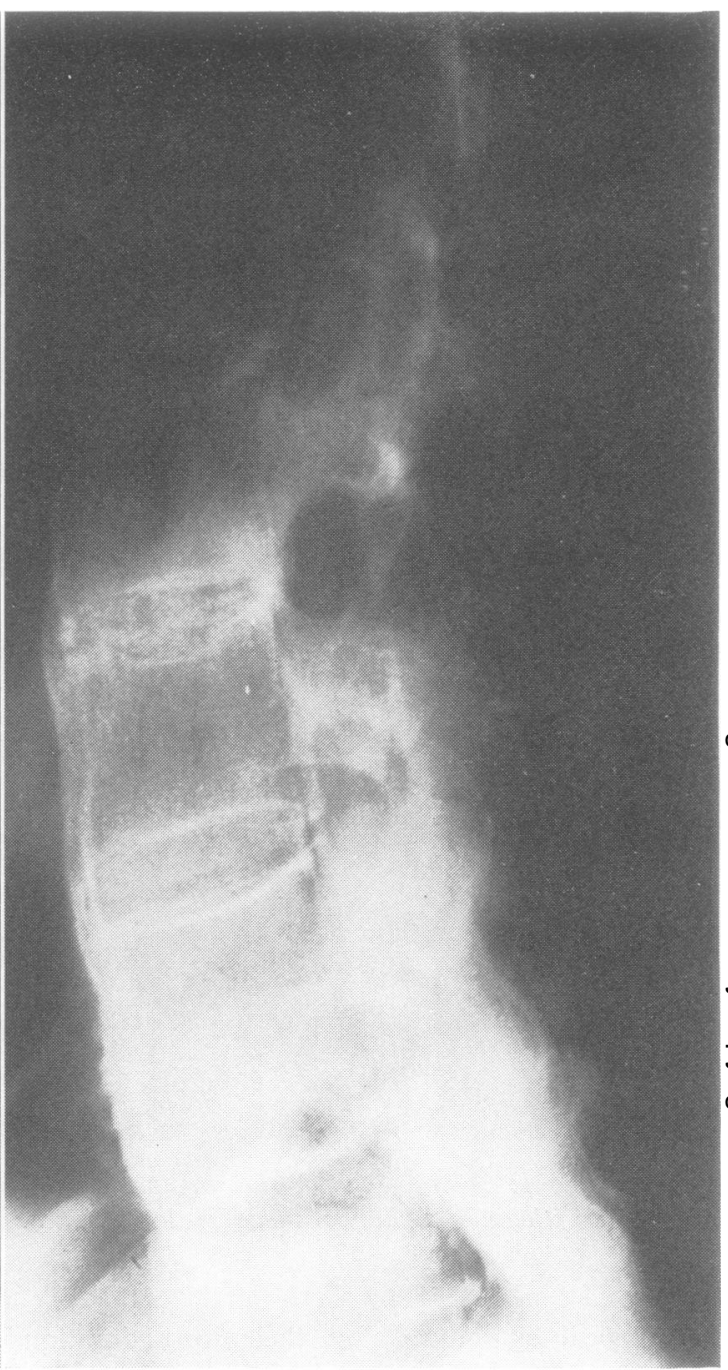

(b)

FIG. 3a and b Case 5. Water soluble myelogram showing posteriorly situated diverticula in the lumbar region.

sively on the laminae and spinous process of a vertebra and eroded the entire posterior surface of the spinal canal in the lumbosacral region. The role of these diverticula in the pathogenesis of the cauda equina syndrome is not clear.

The pathogenesis of ankylosing spondylitis remains unknown (Cruickshank, 1971). Several mechanisms by which the sacral roots could be damaged have been suggested (Thomas et al., 1974). These are demyelination, interference with blood supply by irradiation and spinal arachnoiditis.
Eleven of the 24 patients in this series and in those previously reported in the world literature (Table 1) had never been treated with radiotherapy (case 3 of this study; case 1 of Bowie and Glasgow, 1961; cases 2 and 3 of Hauge, 1961 ; three cases of Russell et al., 1973; case 1 of Gordon and Yudell, 1973; case 3 of Thomas et al., 1974.) Furthermore delayed postirradiation myelopathy occurs after about one year and invariably within five years of irradiation (Zeman and Samorajski, 1971) whereas in all these cases the cauda equina syndrome developed between 17 and 
40 years after irradiation. Hence delayed postirradiation effects are unlikely to be the cause of the cauda equina syndrome.

The possibility that spinal arachnoiditis damages the roots of the cauda equina may be examined by a study of time relations between the onset of symptoms and the findings at laminectomy and necropsy (Matthews, 1968). However, laminectomy has been performed in only four cases (Hauge, 1961; Lee and Waters, 1962; Gordon and Yudell, 1973) and necropsy in only one case (Matthews, 1968). The dense subarachnoid fibrous tissue described by Hauge (1961) in a patient who underwent a laminectomy one year after the onset of symptoms (case 2) contrasted with the less dense subarachnoid fibrous tissue found in the patient operated on two years after the onset of symptoms. However, no arachnoiditis was found at operation in the patient described by Lee and Waters (1962) four years after the onset of symptoms or at necropsy in case 4 of Matthews (1968) ten years after the onset of symptoms. Adhesions of nerve roots to a dense fibrous arachnoid mater were found at laminectomy in Gordon and Yudell's (1973) third case, but no time relation to the onset of symptoms was stated. Matthews (1968) concluded that arachnoiditis may be present at the onset of the neurological complications but later becomes inactive or even resolved. This possibility is supported by the raised cerebrospinal fluid protein in the acute stage of the disease (Boland et al., 1948). Furthermore, most of the reported patients develop their symptoms over a few months and then progress very slowly or not at all.

Another possible mechanism has been postulated by Matthews (1968). Within the cranium enlarging arachnoid cysts may be formed by arachnoid adhesions which form blind pouches into which cerebrospinal fluid is forced by the pumping action of arterial expansion (Dott, 1962). If a similar mechanism operated in the spinal cord and if the bone were abnormally soft, as suggested by the compression of the vertebral bodies by the aorta, diverticula may be formed from localised pressure within the spinal canal and the sacral nerve roots could be damaged by the same expansive process. A large arachnoid cyst causing cord compression at a lower dorsal level in a patient with ankylosing spondylitis has been described (Goldenberg and Logothetis, 1961). Direct compression of nerve by abnormal bony structures does not seem to be the major cause of the cauda equina syndrome as the bony ankylosis does not encroach on the intervertebral foramina (Thomas et al., 1974). Similar syndromes involving the cauda equina have been described in other chronic arthropathies. Ramani and Sengupta (1973) have described a case of tabetic neuroarthropathy of the lumbar spine causing cauda equina compression with paraplegia and retention of urine.

Further studies of laminectomy and necropsy findings are required to unravel the pathogenesis of the cauda equina syndrome in ankylosing spondylitis. It is remarkable that von Bechterew postulated the involvement of the meninges in ankylosing spondylitis in 1893. The true incidence of the cauda equina syndrome in ankylosing spondylitis will be determined only by the recognition that symptoms suggestive of sacral nerve involvement are not due to inflammation of the sacroiliac joint and that the additional screening in the supine position is essential for the visualisation of the posteriorly situated diverticula of the lumbar theca by myelography.

I am indebted to the late Dr G. S. Graveson, and to Dr J. F. Hallpike and Dr P. K. Robinson for their advice and permission to report these cases. I thank Dr E. H. Burrows and Dr P. L. Cook for carrying out the myelography and their useful comments.

\section{REFERENCES}

Bechterew, W. von (1893). Streifigheit der Wirbelsäule und ihre Verkümmung als besondere Erkrankensform. Neurologisches Centralblatt, 12, 426-434.

Boland, E. W., Headley, N. E., and Hench, D. S. (1948). The CSF fluid in rheumatoid spondylitis. Annals of the Rheumatic Diseases, 7, 195-199.

Bowie, E. A., and Glasgow, E. L. (1961). Cauda equina lesions associated with ankylosing spondylitis. Report of 3 cases. British Medical Journal, 2, 24-27.

Cruickshank, B. (1971). The pathology of ankylosing spondylitis. Clinical Orthopaedics and Related Research, 74, 43-58.

Dott, N. (1962). Introductory remarks on hydrocephalus. Developmental Medicine and Child Neurology, 4, 259-262.

Goldenberg, G. J., and Logothetis, J. (1961). Neurological manifestations in 2 cases of ankylosing spondylitis. Lancet, 1, 448-450.

Gordon, A. L., and Yudell, A. (1973). Cauda equina lesion associated with rheumatoid spondylitis. Annals of Internal Medicine, 78, 555-557.

Hauge, T. (1961). Chronic rheumatoid polyarthritis and spondylarthritis associated with neurological symptoms and signs occasionally simulating an intraspinal expansive process. Acta Chirurgica Scandinavica, 120, 395-401.

Lee, M. L., and Waters, D. J. (1962). Neurological complications of ankylosing spondylitis. British Medical Journal, 1, 798.

McGill, I. G. (1966). An unusual neurological symptom associated with ankylosing spondylitis. Guy's Hospital Reports, 115, 33-36. 
Matthews, W. B. (1968). Neurological complications of ankylosing spondylitis. Journal of the Neurological Sciences, 6, 561-573.

Ramani, P. S., and Sengupta, R. P. (1973). Cauda equina compression due to tabetic arthropathy of the spine. Journal of Neurology, Neurosurgery, and Psychiatry, 36, 260-264.

Rosenkranz, W. (1971). Ankylosing spondylitis: Cauda equina syndrome with multiple spinal arachnoid cysts. Case report. Journal of Neurosurgery, 34, 241-243.
Russell, M. L., Gordon, D. A., Ogryzlo, M. A., and McPhedron, R. S. (1973). The cauda equina syndrome of ankylosing spondylitis. Annals of Internal Medicine, 78, 551-554.

Thomas, D. J., Kendall, M. S., and Whitfield, A. G. W. (1974). Nervous system involvement in ankylosing spondylitis. British Medical Journal, 1, 148-150.

Zeman, W., and Samorajski, T. (1970). Effects of irradiation on the nervous system. In Pathology of Irradiation. Edited by Charles C. Berdjis. Williams and Wilkins: Baltimore. 